Subsequent to the workshops, reporters stated their interest in enhancing the quality and depth of news reports on human-wildlife interactions. Initial results indicate that the workshops have been successful in improving the sensitivity of news reports on wildlife residing in and around human habitation. People in India have traditionally accepted the presence of wildlife in their vicinity; retaining this acceptance is crucial for the long-term viability of many threatened species. The media can shape public perceptions of wildlife, and interactions between scientists, conservationists, park managers and journalists are crucial for accurate and responsible reporting on conflict.

VIDYa Athreya and Divya Vasudev Wildlife Conservation Society, India Program, Bangalore, India

E-mail vasudev.divya@gmail.com

\section{Exploring the challenges and opportunities for biodiversity offsets}

The uptake of biodiversity offsets as a mechanism for mitigating the residual impacts of development on species and ecosystems has increased rapidly in recent years, with offset frameworks and/or policies emerging most recently in countries including Liberia, Mozambique and Mongolia. Extensive guidance is available on best practice in biodiversity offsetting and this is supported by an increasing body of scientific research. However, it is widely acknowledged that biodiversity offsetting faces a host of challenges if it is to deliver positive outcomes for biodiversity conservation.

With support from the Arcus Foundation, Fauna \& Flora International (FFI) led a review of the current state of biodiversity offsets, to support the effective implementation of offsetting policy. FFI and collaborators assessed established national and sub-national offsetting schemes in the United States (led by Rebecca Kormos, a Visiting Scholar at the University of California, Berkeley) and Australia, as well as the more recent development of offset policy and practice in South Africa. The review examined case studies in these three countries and elsewhere to better understand barriers and enabling factors for the effective implementation of offsetting policy and the positive and negative outcomes for biodiversity, identifying lessons learned and key considerations for informing emerging offset policy and implementation.

To share this learning and further explore the many dimensions of applying biodiversity offsetting policies in diverse contexts, FFI hosted a 3-day Biodiversity Offsets Learning Event in July 2015, in Cambridge, UK. The event brought together 55 FFI staff, partners and government representatives from Australia, Belize, Brazil, Georgia, Guinea, Indonesia, Kyrgyzstan, Liberia, Namibia, Nicaragua, Philippines, Singapore, South Sudan, Tajikistan, Uganda, and the UK, and aimed to build capacity, establish peer support networks, and share experience and learning on the development of biodiversity offsets and the challenges associated with their implementation. The event also saw the launch of FFI's biodiversity offset animation (https:// vimeo.com/136186136) and was supported by graphic facilitation expert Danny Burgess, who produced some excellent live scribing of the key issues discussed. On the final day, FFI staff and partners were joined by 30 representatives from mining and energy sectors, environmental consultancies, financial lenders, NGOs and research institutions to consider the learning to date, and next steps.

A range of issues arising from the implementation of offsets at national, sub-national and site levels were identified and explored, including those relating to policy and politics, enforcement and compliance monitoring, institutional capacity and resourcing, financing, timelines, coordination and stakeholder engagement, socioeconomic considerations, methods and metrics. Although the barriers to the effective implementation of biodiversity offsetting policy are many and challenges abound, there are some indications that biodiversity offsets can, in certain cases and as a last resort after the full application of the mitigation hierarchy, contribute towards biodiversity conservation objectives.

NICKY JENNER Fauna \& Flora International, Cambridge, UK E-mail nicky.jenner@fauna-flora.org 